\title{
LA MIRADA ANDALUZA DE LORCA (POETA) EN NUEVA YORK
}

\author{
Ángel Estévez Molinero
}

Creemos oportuno, de salida, realizar dos matizaciones al título que portica nuestro trabajo para evitar posibles interpretaciones reductoras. En primer lugar, la calificación de mirada 'andaluza' debe entenderse, desechando minimalismos localistas, con el sentido universal que el propio Lorca le asigna en su conferencia Un poeta en Nueva York cuando, recordando su salida de esta ciudad y su llegada a Cuba, escribe: "... el barco se aleja y comienzan a llegar, palma y canela, los perfumes de la América con raíces, la América de Dios, la América española. ¿Pero qué es esto? ¿Otra vez España? ¿Otra vez la Andalucía mundial?" 1 . Insistimos: «la Andalucía mundial». La segunda matización se refiere a la actitud de quien verbaliza la mirada y esta actitud es la de un poeta; de ahí la precisión parentética que hacemos, apoyándonos, una vez más, en el propio autor, que así creyó conveniente explicitarlo al indicar: "He dicho «un poeta en Nueva York» y he debido decir «Nueva York en un poeta»" (p. 111). Se sobrepasan, con ello, los límites de lo meramente descriptivo y se afianza la voz en los dominios del hablante lírico, transformando los referentes poetizados en referencia última del propio yo; de esta forma, la realidad presentada se convierte en representación del paisaje íntimo del poeta, descubriendo desde él y fuera de él, mediante traslaciones metafóricas, imágenes y símbolos, las angustias, los deseos, la soledad que él siente y que universaliza solidariamente en cuanto hombre.

Así ha procedido Lorca en los libros que, dentro de su trayectoria poética, preceden a Poeta en Nueva York, fundamentalmente en Poema del cante jondo, Canciones y Romancero gitano, construyendo la Andalucia mítica que, sobre lo restrictiva y escenográficamente localista, se eleva a la categoría de símbolo universal y que el poeta utilizará para contrapuntear su visión de la megápolis neoyorquina. En este sentido, y como resultado de la confrontación, la mirada que Lorca verbaliza en Poeta en Nueva York "revela, pues, no sólo la ausencia del mito, sino el sistemático asesinato de las figuras míticas y la destrucción persistente de toda señal de mítica significación por el mundo de los símbolos negativos", según Gustavo Correa² ${ }^{2}$ Se reitera, así pues, el paradigma básico que articula, una y otra vez, el pensamiento lorquiano en interjuego permanente de fórmulas antitéticas y que confluye sistemáticamente en lo que Greimas denomina 'eje temático', entendiendo por tal "el común denominador de los dos términos" que posibilitan el discurso dialéctico o el

\footnotetext{
${ }^{1}$ Federico García Lorca, "Un poeta en Nueva York", en Poesía, 23-24, Madrid, Ministerio de Cultura, 1986, pp. 111-126 (125).

${ }^{2}$ Gustavo Correa, La poesía mítica de Federico García Lorca, Madrid, Gredos, 1975, p. 171.
} 
"fondo del cual se destaca la articulación de la significación" ${ }^{3}$. Desde este punto de vista, el amor, con una clara dimensión panerótica y panenteísta, queda tensionado por la dialéctica de los contrarios, y el duelo de subespacios antonímicos ${ }^{4}$ que sostienen las fuerzas positivas (vida, naturaleza, libertad) y las negativas (muerte, desnaturalización, represión), resuelto a favor de éstas, instituye como tema nuclear la frustración ${ }^{5}$. Ésta se manifiesta en un sentido tanto metafísico como histórico, es decir, en un doble plano -con frecuencia difícilmente disociable- ontológico y social, que proyecta al poeta, más allá de su yo y de las circunstancias que lo rodean, hacia la solidaridad con todos los marginados raciales y sexuales (gitanos, negros, homosexuales, mujeres...), cercenados por la sociedad y la moral imperantes. Y esto es algo que, trascendiendo la exterioridad escenogrática y los referentes corticales, constituye ese «fondo del cual se destaca la articulación de la significación»e ilumina, finalmente, la mirada andaluza de Lorca, pues el poeta no nos va a decir, como claramente advierte, "... lo que es Nueva York por fuera [como tampoco, añadimos, está vista por fuera la Andalucía de los libros anteriores]; ni voy a narrar un viaje, pero sí mi reacción lírica con toda sinceridad y sencillez; sinceridad y sencillez dificilísimas a los intelectuales, pero fácil al poeta"6. Veamos, pues, cómo se materializa la reacción lírica de Lorca y su mirada, 'por dentro', ante la arquitectura extrahumana y el ritmo furioso de Nueva York.

Si "la transmisión de la poesía lorquiana ha sido complicada y azarosa"7, en general, más lo ha sido, particularmente, el libro que nos ocupa. A los problemas de formación y transmisión textual se añaden los interpretativos. Hace ya algunos años, José Ángel Valente ${ }^{8}$ lamentaba que la obra de Lorca estaba siendo bastante mal leída; de entonces a estos días se ha avanzado mucho, tanto en lo que se refiere al esclarecimiento textual como a la interpretación del universo poético/dramático lorquiano. Sin embargo, continúan apareciendo inéditos, se arrojan nuevas luces sobre las viejas sombras e, incluso entre lo ya publicado, persisten problemas textuales e interpretativos en casos muy puntuales, como es el de Poeta en Nueva York. "Ambos problemas, cada uno con su propia y diferente complejidad -tal como señala Díez de Revenga- han sido debatidos durante años y aún lo serán durante bastantes más, porque en su raíz está el conocimiento de la obra del poeta"9.

Digamos, con respecto a los problemas de formación y transmisión del texto, que las primeras ediciones de Poeta en Nueva York, escrito entre 1929 y 1930, aparecen, casi simultáneamente, el año 1940, en Nueva York y México. Aunque se aprecian algunas

\footnotetext{
3 A. J. Greimas, Semántica estructural, Madrid, Gredos, 1971, p. 37.

4 Tenemos en cuenta ad hoc la modelización del espacio artístico según la propuesta de Yiri M. Lotman, Estructura del Texto Artístico, Madrid, Istmo, 1982 (2ª ed.), p. 270 y ss.

5 Miguel García-Posada, "Poesía de la generación del 27: Federico García Lorca, Rafael Alberti", en Francisco Rico (ed.), Historia y crítica de la literatura española, t. 7, Barcelona, Crítica, 1984, pp. 351-382 (359).

${ }^{6}$ Federico García Lorca, op. cit., pp. 111-112.

7 Miguel García-Posada, op. cit., p. 351.

8 José Ángel Valente, "Pez luna", en Trece de Nieve, 2a época, 1-2 (1976), pp. 191-201.

${ }^{9}$ Francisco Javier Díez de Revenga, "Federico García Lorca", en Panorama crítico de la generación del 27, Madrid, Castalia, 1987, p. 173.
} 
diferencias entre una y otra, ambas parten del manuscrito entregado por Lorca a Bergamín en julio de 1936. Pero, apoyándose en tales divergencias, Eutimio Martín suscita en 1972 la pregunta de si existe una versión definitiva; pregunta que él mismo responde, no sin levantar discrepancias, con la bipartición, en 1981, Poeta en Nueva York. Tierra y luna ${ }^{10}$. A esta propuesta se adhiere, con algunas modificaciones en cuanto a la ordenación de los poemas de la primera parte, Miguel García-Posada ${ }^{11}$. Sin embargo, Predmore sostiene que "más del noventa por ciento de Poeta en Nueva York, en su forma actual, refleja la ordenación que le dio Lorca en 1935"12; se apoya Predmore en la autoridad de un contemporáneo y amigo de Lorca, como Bergamín, así como en la opinión de Ángel del Río, que vivió estrechamente el proceso de creación del libro. Claro que, con anterioridad incluso, Eutimio Martín recurre al testimonio de Luis Rosales, también contemporáneo y amigo de Lorca, del que obtiene la siguiente declaración: "A diferencia de Diván del Tamarit, que yo le vi entregar personalmente en la universidad de Granada, no recuerdo que me haya hablado nunca de un manuscrito [en referencia a Poeta en Nueva York] definitivo"13. Puede deducirse, pues, que la polémica al respecto no está, ni mucho menos, cerrada ${ }^{14}$.

A tales problemas, cuyo esclarecimiento debe, indudablemente, aportar luces más diáfanas para la lectura del libro, se añaden los problemas interpretativos. De inmediato llama la atención el contraste de Poeta en Nueva York con respecto a los libros anteriormente escritos por Lorca, tanto desde el punto de vista formal como a nivel contenidístico. Según Correa, "Poeta en Nueva York nos asombra a primera vista por su aparente cambio radical del mundo poético a que estamos acostumbrados"15. Formalmente, como ha dicho Luis Cernuda, hay que "reconocer como cualidad rara en Lorca que no le deslumbró el éxito del Romancero ni quiso asegurarlo siguiendo el rumbo que le marcaba dicho tipo de verso, docilidad al éxito que sin duda sus lectores esperaban de él"16. Pero es que, además del cambio de verso y estrofa populares por el versolibrismo, se produce el desplazamiento del mundo rural al mundo urbano, de la sociedad agraria a la industrial, de la polis a la megápolis, del milenario sincretismo cultural de Andalucía al artificial abigarramiento cosmopolita de Nueva York, de un ámbito enraizado en lo sagrado a un espacio desenraizado espiritualmente. La consecuencia de ello es que "trasladado el poeta a un ambiente dominado casi exclusivamente por la civilización mecánica, se halla de pronto privado de su espontánea y natural comunicación con el mundo afirmativo de la naturaleza

10 Cfr. Federico García Lorca, Poeta en Nueva York. Tierra y luna, ed. de Eutimio Martín, Barcelona, Ariel, 1981; para la pregunta supra abierta, véase del mismo, "¿Existe una versión definitiva de Poeta en Nueva York de Lorca?", Ínsula, 310 (1972), pp. 1 y 10.

11 Cfr. Federico García Lorca, Obras, 2 vols., ed. de Miguel García-Posada, Madrid, Akal, 1982.

12 Richard Predmore, Los poemas neoyorquinos de García Lorca, Madrid, Taurus, 1985, p. 15.

13 Eutimio Martín, "Testimonio de Luis Rosales sobre Poeta en Nueva York, de García Lorca", en El País, 29 de enero de 1978 , p. V.

14 Nada aclara al respecto Derek Harris en su edición de Federico García Lorca, Romancero gitano / Poeta en Nueva York / El público, Madrid, Taurus, 1993, si bien resulta tan sugerente como operativa su exhaustiva anotación de las variantes textuales de la obra que nos ocupa.

15 Gustavo Correa, op. cit., p. 163.

${ }^{16}$ Luis Cernuda, Estudios sobre poesía española contemporánea, Madrid, Guadarrama, 1975 (4ª ed.), p. 167. 
cósmica, y su mundo interior sufre una caída que produce un derrumbamiento momentáneo de todos sus valores"17. El poema titulado Vuelta de paseo contiene, al respecto, las claves básicas de esa caída del mundo interior de Lorca, a que se refiere Correas, ejemplificada intensivamente por su estructura circular con el verso, «Asesinado por el cielo», que inicia y cierra la composición; o, por citar otro ejemplo de los muchos posibles, la aurora -en el poema de igual título- pasa de ser un símbolo emblemático, tradicionalmente positivo, a una representación negativa que tiene "cuatro columnas de cieno / y un huracán de negras palomas / que chapotean las aguas podridas" (p. 133) ${ }^{18}$.

Es innegable que, por contraste con libros anteriores, las nuevas formas y los nuevos contenidos, así como la actitud que Lorca adopta frente a la realidad neoyorquina, nos sitúan ante un nuevo lenguaje poético, superador en buena medida de los modos culteranos que tanto habían atraído a los poetas del 27; sin embargo, según Marie Laffranque ${ }^{19}$, Lorca sobrepasa pronto tal influencia, por más que "la filiación barroca, gongorina, de la metáfora lorquiana, es en este punto un hecho central al que he prestado la atención precisa en mi estudio sobre Poeta en Nueva York", matiza García-Posada ${ }^{20}$. En cualquier caso, y sea mayor o menor esta presencia culterana, resulta obligado referirse a la irrupción del elemento surrealista que, por muy matizable que sea, marca diferencias con respecto a libros anteriores. Con el surrealismo, y más concretamente con el surrealismo francés, parece conectar el tono de protesta y denuncia que el propio Lorca manifiesta en su conferencia $U n$ poeta en Nueva York y que también ha sido destacado por Cernuda, Belamich y Predmore ${ }^{21}$, entre otros. Ahora bien, conviene tener en cuenta que la consciencia de la injusticia, como ha precisado Cernuda, era algo a lo que "ya estaba predispuesto Lorca por motivos personales íntimos"22; y conviene recordar, desde otra perspectiva, que "los elementos oníricos -según Dámaso Alonso- son lo que da transmundo y misterio a la poesía de Federico desde sus primeras canciones, mucho antes de todo superrealismo"23. Podemos ampliar el campo de las matizaciones que tienden a dejar la cuestión surrealista en una particular interpretación lorquiana, incorporando las opiniones de especilistas en la materia como Paul Ilie o Derek Harris, para quien Lorca destacaba en sus poemas lo que él mismo llamaba la emocion pura, descarnada, desligada del control lógico; más aún, García-Posada llega a negar, en las conclusiones de su análisis estilístico de Poeta en Nueva York, el

\footnotetext{
17 Gustavo Correa, op. cit., p. 164.

18 Federico García Lorca, Romancero gitano / Poeta en Nueva York / El público, ed. de Derek Harris, Madrid, Taurus, 1993; citaremos en lo sucesivo por esta edición en lo concerniente a tales libros, indicando entre paréntesis la página correspondiente. En el caso de Poema del cante jondo, lo haremos por la edición de Allen Josephs y Juan Caballero, Madrid, Cátedra, 1978 ( $2^{\mathrm{a}}$ ed.), mientras que seguiremos, para las demás referencias, las Obras completas, 2 vols., Madrid, Aguilar, 1980 ( $21^{\text {a }}$ ed.).

${ }_{19}$ Marie Laffranque, Les idées esthetiques de F. G. L., París, Centre de Recherches Hispaniques, 1967, p. 115.

${ }^{20}$ Miguel García-Posada, "Poesía de la generación del 27: Federico García Lorca, Rafael Alberti", op. cit., p. 361; para el estudio a que se refiere, cfr. Miguel García-Posada, Lorca: Interpretación de "Poeta en Nueva York», Madrid, Akal, 1981.

${ }^{21}$ Cfr. Luis Cernuda, op. cit.; André Bellamich, Lorca, Paris, Gallimard, 1981; Richard Predmore, op. cit.

22 Luis Cernuda, op. cit., p. 168.

23 Dámaso Alonso, Poetas españoles contemporáneos, Madrid, Gredos, 1969 (3ª ed.), p. 173.
} 
surrealismo formal del libro $^{24}$. Sea cual sea, no obstante, el componente surrealista, lo importante, a nuestro entender, es la funcionalidad comunicativa que de él extraen, además de Lorca, poetas como Aleixandre, Cernuda o Alberti (todos ellos, por cierto, andaluces); en este sentido, nos parece muy esclarecedora la opinión de Fernando Ortiz al indicar que el surrealismo "nunca pretendió negar lo sagrado, y lo que en él buscan y encuentran los poetas andaluces es una forma más libre de estructurar el discurso artístico y, también, un cauce para expresar su descontento, su rebeldía, su radicalismo antiburgués"25. Más adelante retomaremos algunos de estos aspectos; interesa, por ahora, retener que la pretensión lorquiana de trasmitir la emoción pura, descarnada, desligada del control lógico, es decir, con la libertad que hubiera negado el sometimiento a las normas convencionales, se traduce con gran coherencia en la adecuación métrico-temática que, bien sea deliberadamente pretendida o sorpresivamente intuida, ofrece Poeta en Nueva York.

El cambio formal (versolibrismo) y temático (nuevos referentes de la civilización anglosajona y de la deshumanización urbana), así como una actitud desencandada y pesimista que se registra en un tono acusador y apocalíptico, constituyen una evidencia inmediata en el libro que nos ocupa y parecen resquebrajar el sentido unitario del universo poético lorquiano y la base poética, muy precisa y coherente que lo sustenta. Ahora bien, el cambio con respecto a los libros anteriores afecta a lo más cortical de la expresión; es, pues, un cambio más accidental que esencial, porque los referentes elegidos confluyen, a fin de cuentas, en ese «fondo del cual se destaca, según hemos oído a Greimas, la articulación de la significación». Podrá cambiar, en función de los referentes externos, el término metafórico, la imaginería o el símbolo, incluso «desligados del control lógico», como por lo demás frecuentemente ocurre; pero, subyaciendo a tales referentes, persiste el plano metaforizado que podemos esquematizar en un proceso básico de amor, falta de libertad y frustración, diversificado y trascendido por efectos de la solidaridad que Lorca proyecta hacia todos los marginados y de la protesta que eleva contra todo aquello y aquéllos que atentan contra la realización humana; en este sentido, conviene destacar la funcionalidad de la metáfora como elemento conector, según Concha Zardoya, de planos y campos semánticos múltiples ${ }^{26}$. Avisados consiguientemente sobre lo que Unamuno llamaba el engañoso realismo de lo aparencial, por ser una tentación permanente en un estilo -el lorquiano- que ha sido caracterizado por Hönig como el triunfo de la realidad sensual y que García-Posada califica como un discurso de lo concreto $^{27}$, interesa atender a las claves básicas que fluyen por toda su obra asegurando la unidad y vertebración del universo poético. Ya en las Suites, por ejemplo, junto a

\footnotetext{
24 Cfr., para las distintas perspectivas, Paul Ilie, Los surrealistas españoles, Madrid, Taurus, 1972; Derek Harris, García Lorca: "Poeta en Nueva York», Londres, Grant \& Cutler, 1978, así como "¿Escritura automática: lectura racional? Una pesquisa comparativa acerca del surrealismo en España", Litoral, 174-176 (1987), pp. 190-206; Miguel García-Posada, Lorca: Interpretación de "Poeta en Nueva York», op. cit.

25 Fernando Ortiz, "Actualidad de la poesía andaluza contemporánea", en Mis tradiciones (Poéticas y poetas andaluces), Córdoba, Eds. de la Posada, 1988, pp. 103-108 (106).

${ }^{26}$ Cfr. Concha Zardoya, Poesía española del siglo XX. Estudios temáticos y estilísticos, Madrid, Gredos, 1974.

27 Edwing Höning, García Lorca, Barcelona, Laia, 1963, y Miguel García-Posada (ed.), Obras, op. cit., respectivamente.
} 
poemas ligeros y alegres, encontramos otros que reflexionan con inquietud y desazón sobre el tiempo, la soledad o la muerte; esta segunda línea, según Bellamich, "marca el punto de partida del gran río negro, meditativo y visionario, radicalmente pesimista que, corriendo por debajo de las Canciones y del Romancero gitano, anegará Poeta en Nueva York y el Diván del Tamarit"28. También Charles Marcilly ha documentado en las Suites huellas de la crisis personal que explotaría de forma abierta en Poeta en Nueva York ${ }^{29}$. Por su parte, Allen Josephs y Juan Caballero apuntan que donde "mejor se ve la presencia de Andalucía sería en los dos libros [Poema del cante jondo y Romancero gitano] que presentamos, cuyos temas son andaluces por excelencia. Sin embargo, no se trata de exclusividad; es precisamente una visión andaluza la que observa la gran metrópoli de Nueva York con tanto horror"30.

Pero ya con anterioridad a los libros mencionados, y en una obra en gran manera primeriza como es el Libro de poemas, podemos encontrar gérmenes claros de lo que serán el tono y la actitud proyectados en Poeta en Nueva York. Tomemos, como ejemplo, el poema titulado Vuelta de paseo, significativamente porticado por estos versos de Luis Cernuda: «Furia color de amor, / amor color de olvido»:
Asesinado por el cielo, entre las formas que van hacia la sierpe y las formas que buscan el cristal, dejaré crecer mis cabellos.
Con el árbol de muñones que no canta y el niño con el blanco rostro de huevo. Con los animalitos de cabeza rota y el agua harapienta de los pies secos. Con todo lo que tiene cansancio sordomudo y mariposa ahogada en el tintero.
Tropezando con mi rostro distinto de cada día. ¡Asesinado por el cielo! (pp. 129-130)

Tres aspectos llaman la atención en el poema; en primer lugar, el desmoronamiento del mito ejemplificado en la involución negativa de los elementos cósmicos: el cielo que asesina, el árbol de muñones que no canta, el niño con el blanco rostro de huevo, los animalitos de cabeza rota, el agua harapienta de los pies secos y la mariposa ahogada en el

\footnotetext{
28 André Bellamich, introducción a Federico García Lorca, Suites, Barcelona, Ariel, 1983, p. 22.

29 Charles Marcully, "El pensamiento de Federico", en Los Domingos de ABC, núm. 954, 17 de agosto de 1986, p. 13.

30 Allen Josephs y Juan Caballero, introducción a Poema del cante jondo / Romancero gitano, op. cit., p. 15. Esta visión andaluza, a partir del contraste de la civilización española y, particularmente, andaluza, con la anglosajona, será pormenorizado por el propio Allen Josephs, "Poeta en Nueva York, a medio siglo", Nueva Estafeta, 4 (1979).
} 
tintero; en segundo lugar, la deshumanización, pues las personas se reducen a formas que van hacia la sierpe (= calles y subterráneos del metro) o que buscan el cristal (= habitaciones y oficinas de los rascacielos), aceptando la interpretación de Correa ${ }^{31}$; finalmente, la pérdida de la identidad, patéticamente reflejada en el penúltimo verso: «Tropezando con mi rostro distinto de cada día», cuya causa, según sugieren los versos porticadores de Cernuda, es el mal de amor. Los referentes utilizados en este poema por Lorca para anunciar el asesinato de toda señal de mítica significación, modificados por elementos de signo negativo, podemos ya encontrarlos, con valoración inicial positiva, en Los encuentros de un caracol aventurero, del Libro de poemas, cuyos primeros versos, para facilitar la comparación, creo interesante reproducir: "Hay dulzura infantil / en la mañana quieta. / Los árboles extienden / sus brazos a la tierra. / Un vaho tembloroso / cubre las sementeras, / y las arañas tienden / sus caminos de seda / -rayas al cristal limpio / del aire-. En la alameda / un manantial recita / su canto entre las hierbas. / Y el caracol, pacífico / burgués de la vereda, / ignorado y humilde, / el paisaje contempla. / La divina quietud / de la Naturaleza / le dio valor y fe / y olvidando las penas / de su hogar, deseó / ver el fin de la senda" (I: 12), etc. Pero, premonitoriamente, al final de la senda (metáfora, como los caminos manriqueños, de la vida), encontramos al caracol, tras las experiencias pasadas, aturdido e inquieto contemplando el paisaje. Los referentes, en cualquier caso, mantienen una clara correspondencia en los poemas de ambos libros: dulzura infantil y niños; árboles y árbol; arañas y caracol (más otros animales que aparecen a lo largo de la senda), por una parte, y animalitos, por otra; manantial y agua; aparece, incluso, la mariposa, aunque sea en la apreciación errónea de la rana casi ciega. En el caso del Libro de poemas, los elementos naturales tienen, en principio, un valor positivo, mientras que en Poeta en Nueva York a esos mismos elementos se le han adherido significaciones negativas. Sin embargo, el caracol podrá comprobar a lo largo de la senda que aquella Naturaleza que le dio valor y fe para recorrer el camino, ni tiene tanta quietud ni esta quietud es tan divina, y, por ello, queda aturdido e inquieto, como imagen premonitoria del poeta que, en Vuelta de paseo, se sorprende tropezando con su rostro distinto de cada día. En el mismo Libro de poemas encontramos algunos de estos referentes transmutados en elementos de signo negativo; así, por ejemplo, el árbol de muñones que no canta recuerda estos versos del poema Mañana: "Los árboles que cantan / se tronchan y se secan" (I: 30); el agua harapienta de los pies secos (en imagen, por cierto, explicada detalladamente por Harris $^{32}$ ), parece vitalmente entrevista en estos versos de Manantial: "Mas yo siento en el agua / algo que me estremece... como un aire / que agita los ramajes de mi alma" (I: 120); la mariposa ahogada en el tintero bien pudiera ser aquella de Balada triste "que presa por la araña gris del tiempo / tiene el polen fatal del desengaño" (I: 27); la pérdida de la identidad, ejemplificada en ese tropiezo "con mi rostro distinto de cada día", parece ser el desenlace al que llega "La sombra de mi alma -en el poema de igual título- (que) / huye por un ocaso de alfabetos, / niebla de libros / y palabras" (I: 32); incluso los versos, "Veo la palabra amor / desmoronada" (I: 33), del mismo poema, quieren anticipar los de Cernuda que portican la

\footnotetext{
31 Gustavo Correa, op. cit., p. 165.

32 Derek Harris, "A la caza de la imagen surrealista en Lorca", Ínsula, 368-369 (1977), p. 19.
} 
composición de Poeta en Nueva York a la que nos venimos refiriendo. Son muchas más, indudablemente, las huellas del Libro de poemas que pueden rastrearse en Poeta en Nueva York; por ejemplo, el poema titulado 1910 (Intermedio) comienza: "Aquellos ojos míos de mil novecientos diez..." (p. 131); pero ya Lorca, en el poema Balada triste, fechado en abril de 1918, traduce su nostalgia por la pérdida del paraíso infantil cuando expresa: "¡Qué tristeza tan seria me da sombra! / Niños buenos del prado, / cómo recuerda dulce el corazón / los días ya lejanos..." (I: 29); y, en Norma y paraíso de los negros, nos dice que "Odian la flecha sin cuerpo..." (p. 141), lo que, a la luz metáforica del Poema de la saeta, del cante jondo, podría relacionarse con la interrogación retórica, "¿Que será del corazón / si el Amor no tiene flechas?" (I: 19), de Canción otoñal.

Las conexiones de Poeta en Nueva York con otros libros arraigadamente andaluces del universo lorquiano pueden documentarse con abundancia, e incluso más fácilmente. Pongamos como ejemplo esta estructura sinónima del paradigma de la frustración registrada en los siguientes versos del poema 1910 (Intermedio): "No preguntarme nada. He visto que las cosas / cuando buscan su curso encuentran su vacío" (p. 132), y contrastémoslos con otros de distintos libros. En el poema Camino, incluido dentro del Gráfico de la petenera, del Poema del cante jondo, leemos: "Cien jinetes enlutados, / ¿dónde irán, / por el cielo yacente / del naranjal? / Ni a Córdoba ni a Sevilla / llegarán. / Ni a Granada la que suspira / por el mar" (p. 176). Posteriormente se nos informa, en el poema De profundis, que "Los cien enamorados / duermen para siempre / bajo la tierra seca. / Andalucía tiene / largos caminos rojos. / Córdoba, olivos verdes / donde poner cien cruces, / que los recuerden" (p. 182). En el libro Canciones, y en el poema Canción de jinete, Córdoba se transmuta en símbolo de la "imposibilidad de llegar a algún sitio a donde se quiere ir, se necesita ir, se está yendo y nunca se 1lega"33; sabe el jinete, como sabe y reitera Lorca, que "Aunque sepa los caminos, / yo nunca llegaré a Córdoba" (I: 313). También en el Romancero gitano pueden inventariarse ejemplos; sirvan como muestra concluyente estos versos del Romance de la pena negra: "Soledad, ¿por quién preguntas / sin compaña y a estas horas? / Pregunte por quien pregunte / dime: ¿a ti qué se te importa? / Vengo a buscar lo que busco, / mi alegría y mi persona" (pp. 84-85); pero ya sabía Lorca «que las cosas / cuando buscan su cauce encuentran su vacío» y, por ello, Soledad Montoya, metaforizada en "caballo que se desboca, / al fin encuentra la mar / y se lo tragan las olas" (p. 85). Como puede deducirse, las estructuras oracionales, métricamente distintas y semánticamente sinónimas, instituyen el paradigma de la frustración y de la muerte de los deseos insatisfechos ${ }^{34}$.

En el mismo sentido cabe interpretar ese "¡Agua que no desemboca!", imagen patéticamente reiterada en el poema Niña ahogada en el pozo, subtitulado significativamente (gracias al valor de la unión copulativa) Granada y Newburg, y que tiene claros precedentes en "las hondas cisternas" (p. 154) del Poema de la soleá, en el número 4 de Nocturnos de la

\footnotetext{
${ }^{33}$ Francisco Umbral, Lorca poeta maldito, Madrid, Biblioteca Nueva, 1975 (2 ed.), p. 50.

34 Para todos estos aspectos, cfr. Ángel Estévez Molinero, Federico García Lorca o poética de la libertad, Córdoba, Eds. de la Posada, 1987, así como "De Rivas a Lorca: efectos, en transtextualidad, de oposiciones dialógicas", Glosa 4 (1993) 61-77.
} 
ventana", del libro Canciones: "Al estanque se le ha muerto / hoy una niña de agua. / Está fuera del estanque, / sobre el suelo amortajaảa" (I: 302), así como en el Romance sonámbulo, del Romancero gitano: "Sobre el rostro del aljibe / se mecía la gitana. / Verde carne, pelo verde, / con ojos de fría plata" (p. 78). El pozo, las cisternas, el estanque y el aljibe, así pues, comparten, como sinónimos léxicos, la noción de agua que no desemboca y reproducen el paradigma de lo que, al no ser realizable por no tener salida, representa la frustración y la muerte. Los ejemplos, obviamente, pueden multiplicarse; sin embargo, lo expuesto resulta suficientemente esclarecedor para nuestra pretensión de insistir en el sentido unitario del universo lorquiano, pues las claves básicas, conformadas en paradigmas generadores de traslaciones metafóricas múltiples, se mantienen, con aires de premonición o clara explicitación, desde el principio, construyendo una poética -y recordamos nuevamente a Marie Laffranque- muy precisa y coherente. La ruptura, así pues, que parece marcar en la historia poética lorquiana Poeta en Nueva York, es más aparencial que real, porque, en todo momento, la mirada que verbaliza la realidad contemplada, es una mirada andaluza, que, eso sí, reacciona, sensiblemente herida, ante la pesadilla de la gran metrópoli neoyorquina y, por extensión, ante una civilización, la anglosajona, que choca violentamente con la civilización arraigadamente milenaria, cósmicamente armónica y emblemáticamente sagrada, de la Andalucía mundial. Esa mirada andaluza, tan autóctona como familiarizada con una visión mítica y panteísta de la Naturaleza, es la que permite afirmar a Allen Josephs que toda "la obra de Lorca es inconfundiblemente andaluza e indescifrable sin ella, y es precisamente por ello que el empleo a la inversa de su norma poética, fuera de su propio contexto, en esta visión de un apocalipsis americano tenga tanta severidad, tanta agudeza humana y, en última instancia, tanta universalidad profética"35.

Ahora bien, no se puede negar que Poeta en Nueva York representa un punto de inflexión en el quehacer poético lorquiano que, inexcusablemente, hay que relacionar con la crisis que motiva el viaje del poeta a Norteamérica. Verdad es que la crisis, que ahora explota desgarradamente, estaba ya previamente incubada, como lo prueban las muchas huellas que pueden rastrearse en libros anteriores. Pero no se pueden desdeñar las circunstancias de tipo estético y sentimental que, definitivamente, la desencadenan. Tan imprescindible resulta considerar tales circunstancias para comprender la auténtica dimensión de la crisis, como tener ésta en cuenta si no queremos incurrir en una visión reductora de lo que el libro significa. Por lo demás, los testimonios del propio Lorca al respecto son suficientemente explícitos y aportan, consiguientemente, no pocas luces interpretativas.

La crisis estética, analizada entre otros por Martínez Nadal y Gibson ${ }^{36}$, se desencadena tras la publicación del Romancero gitano, y la reacción de Lorca, harto de la etiqueta de popularismo y gitanería que el libro le ha deparado, es altamente ilustrativa: "el gitanismo -escribirá a Jorge Guillén- me da un tono de incultura, de falta de educacidn y de poeta salvaje que tú sabes bien no soy. No quiero que me encasillen. Siento que me van echando

\footnotetext{
35 Allen Josephs, "Poeta en Nueva York, a medio siglo", op. cit., p. 70.

36 Cfr. Rafael Martínez Nadal, Cuatro lecciones sobre Federico García Lorca, Madrid, Fundación Juan March, 1980; Ian Gibson, Federico García Lorca, I, Barcelona, Grijalbo, 1985.
} 
cadenas"37. Desechando, así pues, interpretaciones que, por localistas, resultan reductoras, conviene aceptar, como indica Piero Menarini, que "el gitanismo de Lorca no es un hecho meramente español, no es fórmula folklorística de apego morboso al patriotismo popular nacional, sino expresión particular de una época que, a través del discurso artístico, intenta rechazar la sociedad constituida y, con ella, el arte oficial" 38 . Desde esta perspectiva, hay que situar los gitanos del Romancero en la misma línea significativa que, en la lucha dialéctica de opresores/oprimidos, desempeñan en el contexto neoyorquino los negros, los judíos, los niños..., porque todos ellos son, como lo es el propio Lorca por su peculiaridad sexual, seres que margina la sociedad y la moral burguesa. Por ello, continúa Menarini, "no es una casualidad que, recién llegado a América, García Lorca se dirija a las clases marginadas de la sociedad civil, identificables, sobre todo, en los negros: en ellos, por estar apartados parcial o totalmente de la fruición del «bienestar», y, por consiguiente, de los esquemas del correcto vivir burgués, encuentra las instancias primitivas de ingenuidad, pureza, moralidad natural y, sobre todo, libertad instintiva que ya había apreciado en los gitanos"39. Y a propósito de esta libertad cercenada, ¿no había dicho ya Lorca, en 1923, por boca de Mariana Pineda al final de la obra de igual título, "Yo soy la libertad herida por los hombres. / Amor, amor, amor y eternas soledades"? (II: 1047). En esta ocasión, Lorca se camufla tras la voz de Mariana Pineda; pero son otros muchos los momentos en que el propio Lorca, con el patetismo de quien busca su alegría y su persona, canta al amor y a la libertad; así podemos escucharlo, por ejemplo, en el Poema doble del lago Eden, de Poeta en Nueva York, cuando pide: "Pero no quiero mundo ni sueño, voz divina, / quiero mi libertad, mi amor humano / en el rincón más oscuro de la brisa que nadie quiera. / ¡Mi amor humano!" (p. 174). Frente a este deseo de libertad, no deja de ser ciertamente significativo el que esas cadenas, que el poeta confiesa a Guillén le van echando, se transmuten en imagen de la opresión que, como él, sienten esos tres mil judíos que, en el poema Cementerio judio, lloran "porque reunían entre todos con esfuerzo media paloma, / porque uno tenía la rueda de un reloj / y otro un botín con orugas parlantes / y otro una lluvia nocturna cargada de cadenas" (p. 208); o que lamente, en Grito hacia Roma, que haya "un millón de herreros / forjando cadenas para los niños que han de venir" (p. 214). Sistemáticamente, así pues, la utilización del gitano en el Romancero, como la del negro, la del judío o la de los niños en Poeta en Nueva York, hay que considerarla, más allá de las estrecheces tipistas y folflorísticas, como producto, dice Menarini, "de la evolución de los más modernos movimientos de vanguardia europea de comienzos de siglo (primitivismo, negrismo, infantilismo, etc.)" (ibid.); también Maurer sostiene que esta "visión lorquiana de los negros está anclada, como es lógico, en el romanticismo de la epoca"40. Pero uno y otro saben que la auténtica raíz de estas presencias sobrepasa los límites puramente estéticos para llenarse de significaciones más hondas. Así, por ejemplo, indica Maurer, que en "Harlem, el blanco no sólo intentaba evadirse de la

\footnotetext{
${ }^{37}$ Federico García Lorca, Obras completas, t. II, Madrid, Aguilar, 1980, p. 1277.

38 Piero Menarini y Ángel del Río, "Sobre Poeta en Nueva York", en Historia y crítica de la literatura española, op. cit., pp. 392-396 (394).

39 Ibid.

40 Christopher Maurer, "Los negros", en Poesía, op. cit., p. 150.
} 
mecanización, sino también de la moral «puritana». Junto al cliché de la superioridad espiritual del negro se alzaba el de su «amoralidad» (...) Observa el mismo Lorca que en Harlem «lo lúbrico tiene un acento de inocencia que lo hace perturbador y religioso». La idea de que esta minoría no compartiera la moral sexual del grupo dominante debió de interesarle; no es casual que en la "Oda a Walt Whitman" una criatura marginada, un niño negro, sea quien anuncie a los blancos «la llegada del reino de la espiga»"41. O, como dice Menarini comentando el poema Cementerio judío -opinión extensible a todo el libro por su validez-, "la pérdida de sí mismo, de la propia identidad, de la propia esencia humana, que afecta a los negros, a los judíos, a los niños y al mismo poeta, es total en este momento y parece acometer al universo entero" 42 . La raíz de todo ello, precisamos, hay que buscarla en la mirada andaluza del poeta, como él mismo nos aclara: "Yo creo que el ser de Granada me inclina a la comprensión simpática de los perseguidos. Del gitano, del negro, del judío..., del morisco, que todos llevamos dentro. Granada huele a misterio, a cosa que no puede ser y, sin embargo, es (...). Que se ve acorralada y trata de injertarse en todo lo que la rodea y amenaza para ayudar a disolverla" (II: 975). Recordemos, una vez más, para más apuntalar las interrelaciones existentes en el universo lorquiano, cómo en el subtítulo del poema Niña ahogada en el pozo están copulativamente unidas, con lo que ello implica de equivalencia funcional, Granada y Newburg. Y entendamos, desde ese acorralamiento que propicia la imagen de Granada, desde esa comprensión simpática de los perseguidos, el grito de denuncia al "hombre vestido de blanco / [que] ignora el misterio de la espiga" (p. 214), exigiendo el derecho a la libre realización que en justicia les corresponde y que sintácticamente razonan las causales que cierran el compulsivo Grito hacia Roma: "Porque queremos el pan nuestro de cada día, / flor de aliso y perenne ternura desgranada, / porque queremos que se cumpla la voluntad de la Tierra / que da sus frutos para todos" (p. 216).

La crisis abierta por el gitanismo, como puede apreciarse, no se manifiesta en una dimensión unidireccionalmente estética, sino que encierra, en su estructura latente, el germen de la crisis sentimental que había de explotar por esas mismas fechas y de la que se han ocupado, entre otros, Ángel del Río, Fusero, Predmore y Maurer ${ }^{43}$. En el otoño de 1928, según recoge Maurer en el Epistolario, Lorca confiesa a Jorge Zalamea que está pasando "uno de los estados más dolorosos que he tenido en mi vida"44. El detonante directo de la crisis sentimental, desencadenada entre abril y julio de 1928, parece haber sido la ruptura con su amante, el escultor Emilio Aladrén Perojo. Cuando, después de haber estado en Zamora impartiendo una conferencia sobre Pedro Soto de Rojas, escribe a José Antonio Rubio Sacristán, en cuya casa se había alojado, Lorca explicita las razones de esta crisis ${ }^{45}$.

\footnotetext{
${ }^{41}$ Íd., p. 149.

42 Piero Menarini, op. cit., p. 393.

43 Cfr. Ángel del Río, Estudios sobre literatura española contemporánea, Madrid, Gredos, 1966; Clemente Fusero, García Lorca, Milan, Dall'Ogio, 1969; Richard Predmore, Los poemas neoyorquinos de García Lorca, op. cit., y Christopher Maurer (ed.), "Catorce cartas", en Poesía, op. cit., pp. 33-90.

44 Christopher Maurer, Epistolario de F. G. L., t. II, Madrid, Alianza, 1983, p. 119.

45 Reproducimos el fragmento de la carta recogido por Ch. Maurer, apud la "Presentación" a Poesía, op. cit., p. 11: "... tú ya sabes que en Zamora yo estaba preocupado, y con razón. He atravesado (estoy atravesando) una
} 
La incidencia de esta situación se refleja, de una forma existencialmente desgarrada, en Poeta en Nueva York, cuyo tema nuclear no es otro que el amor, pero en una dimensión de angustiosa vaciedad, en una atmósfera de soledad absoluta y en un punto de pérdida de identidad que lleva al poeta a lamentar elegiacamente los paraísos perdidos de la infancia, a la añoranza del mundo aproblemático e ingenuo de los ninos, a la solidaridad con la libertad instintiva y la moral natural de los negros, a la protesta consiguiente contra todo lo que obstaculiza la realización del ser humano, al clamor contra todo lo antinatural, deshumanizado, materialista, artificial y sin raíces.

La crítica, en general, poniendo más énfasis en unos u otros aspectos según los casos, viene a coincidir en ello. Así, por ejemplo, Marie Laffranque considera que "el personaje esencial de este libro no es la muerte, sino el amor martirizado y el hueco que deja su ausencia en la vida, la cual, sin embargo, sólo existe gracias a él"46. También Correa entiende que la imagen del "hueco como la expresión más exacta de la pérdida del ser, subraya en forma angustiosa el sentimiento de soledad que constituye el subsuelo emocional de donde se nutre esta poesía"47. Para García-Posada existen dos temas nacleares, la soledad y la muerte, complementados por otros motivos inquietantes como la soledad amorosa, la infancia perdida, la denuncia de la gran ciudad, etc. ${ }^{48}$. Predmore, en fin, destaca el carácter de denuncia social, así como el tema del amor homosexual y el de la pérdida de la fe religiosa ${ }^{49}$.

La soledad, en efecto, y más precisamente la soledad amorosa del poeta, queda patéticamente reflejada en este verso del poema Tu infancia en Menton: "¡Amor de siempre, amor, amor de nunca!" (p. 136), o en estos otros de Nocturno del hueco: "Dentro de ti, amor mío, por tu carne / ¡qué silencio de trenes boca arriba!, / ¡cuánto brazo de momia florecido! / ¡qué cielo sin salida, amor, qué cielo!" (p. 189). Esta soledad de amor hay que asociarla con la crisis de identidad que hace tropezar a Lorca "con mi rostro distinto de cada día" (p. 130), como sugieren, incluso por su estructura paralela, los versos del poema Navidad en el Hudson: "¡Oh brisa mía de límites que no son míos! / ¡Oh filo de mi amor, oh hiriente filo!" (p. 164). El poeta, en esta situación de vacío y desorientación, pero, al mismo tiempo, de búsqueda angustiosa de realización personal, viene a ser como "el campo [que] se muerde la cola para unir las raíces en un punto / y el ovillo [que] busca por la grama su ansia de longitud insatisfecha" (p. 160, de Paisaje de la multitud que orina). Buscará para ello referentes en los que asegurar su tambaleante mundo interior. Sin embargo, como le ha

\footnotetext{
de las crisis más hondas de mi vida. Es mi destino poético. No se puede jugar con lo que nos da la vida y la sangre, porque se carga uno de cadenas cuando menos lo desea. Ahora me doy cuenta qué es eso del fuego de amor de que hablan los poetas eróticos, y me doy cuenta, cuando tengo necesariamente que cortarlo de mi vida para no sucumbir. Es más fuerte [de lo] que yo sospechaba. Si hubiera seguido alentándolo, habría acabado con mi corazón. Tú nunca me habías visto más amargo, y es verdad. Ahora estoy lleno de desesperanza, sin ganas de nada, tullido", etc.

46 Marie Laffranque, Les idées esthetiques de F. G. L., op. cit., p. 216.

47 Gustavo Correa, La poesía mítica de F. G. L., op. cit., p. 179.

48 Cfr. M. García-Posada, Lorca: Interpretación de «Poeta en Nueva York», op. cit., p. 68 y ss.

${ }^{49}$ Richard Predmore, Los poemas neoyorquinos de García Lorca, op. cit., p. 75 y ss.
} 
ocurrido a los jinetes de las Canciones y de Poema del cante jondo, a Mariana Pineda, o a Soledad Montoya en el Romancero, sabe ya Lorca «que las cosas / cuando buscan su cauce encuentran su vacío». Sobreviene, en consecuencia, la melancólica rememoración del paraíso de la infancia, porque, entonces, "Aquellos ojos míos de mil novecientos diez / no vieron enterrar a los muertos, / ni la feria de ceniza del que llora por la madrugada, / ni el corazón que tiembla arrinconado como un caballito de mar" (p. 131), en 1910 (Intermedio); y la rememoración introduce, emotivamente, un lamento elegiaco en los versos del Poema doble del lago Edem: "¡Ay, voz antigua de mi amor, / ay, voz de mi verdad; / ay, voz de mi abierto costado, / cuando todas las cosas manaban de mi lengua / y el césped no conocía la impasible / dentadura del caballo!" (pp. 173-174). Pero la voz antigua y verdadera de ese amor ha sido cercenada y el poeta exigirá, en el mismo poema, su libertad, su amor humano; como lo pedirá también, en el poema Tu infancia en Menton, con grito desgarrado de protesta: "¡Oh, sí! Yo quiero. ¡Amor, amor! Dejadme. / No me tapen la boca los que buscan / espigas de Saturno por la nieve / o castran animales por un cielo, / clínica y selva de la anatomía" (p. 136). Los paradigmas, pues, tensionados en la lucha antitética amor/represión, libertad/autoridad, vida/muerte..., como puede apreciarse, se reiteran una y otra vez. Lo importante para nuestros propósitos, sin embargo, no es tanto este amor que, por su peculiaridad sexual, sufre la marginación y la condena de la moral burguesa imperante, cuanto la crisis de identidad que conlleva. Y es de nuevo una mirada andaluza la que busca, entre la arquitectura extrahumana y el ritmo furioso de Nueva York, los referentes que favorezcan la recuperación de la identidad perdida y logren subvertir la soledad en que se anega. Veamos algunos de estos referentes que, sin embargo, la realidad neoyorquina estrangula de manera insensible y reiterada.

Lorca procede de un contexto rural caracterizado por un tipo de estructura agraria y por la existencia de pequeñas ciudades, lo que contrasta con el nivel de industrialización y con la megápolis norteamericana. El panerotismo lorquiano, que tiene mucho -o todo- de panteísmo, de comunión erótica con la Naturaleza, es un rasgo enraizado en su origen andaluz (y que con él comparten otros muchos autores andaluces); ya Ortega y Gasset, en su Teoría de Andalucía, había destacado esta especie de panteísmo del pueblo andaluz como un rasgo configurador de su personalidad al escribir: "Vive, pues, este pueblo referido a su tierra, adscrito a ella en forma distinta y más esencial que otro ninguno"50. El mismo Lorca, en declaración recogida en 1934 por José R. Luna, confiesa: "Amo a la tierra. Me siento ligado a ella en todas mis emociones. Mis más lejanos recuerdos de niño tienen sabor de tierra. La tierra, el campo, han hecho grandes cosas en mi vida" (II: 1058). Pero este amor a la tierra y al campo choca frontalmente con la realidad desnaturalizadamente urbana de Nueva York en la que "no habrá paraíso ni amores deshojados" (p. 134, La aurora) y donde el poeta lamenta, en Nueva York. Oficina y denuncia, haber "venido para ver la turbia sangre" (p. 204). Desde esta ligazón a la tierra, y para preservar a Stanton de esas monedas que "en enjambres furiosos / taladran y devoran abandonados niños" (p. 132, La aurora), es por lo

50 José Ortega y Gasset, "Teoría de Andalucía", en Andalucía, sueño y realidad, Granada, Biblioteca de Cultura Andaluza, 1984, p. 244. 
que le pide, en el poema titulado El niño Stanton: "Stanton, vete al bosque con tus arpas judías, / vete para aprender celestiales palabras / que duermen en los troncos, en nubes, en tortugas, / en los perros dormidos, en el plomo, en el viento, / en lirios que no duermen, en aguas que no copian, / para que aprendas, hijo, lo que tu pueblo olvida" (p. 180). Lo que Lorca, añadimos, no ha olvidado. La gran metrópoli de Nueva York, en cualquier caso, no es el espacio apropiado para la realización del ser humano ni para contrarrestar los efectos de la crisis de identidad que asola al poeta, porque aquí "La luz es sepultada por cadenas y ruidos / en impúdico reto de ciencia sin raíces" (p. 134, La aurora), luego no es referente válido para afirmar sus señas de identidad.

Tampoco encontrará en Nueva York el componente sagrado tan característico de la cultura andaluza, pues, como expresa en la Oda a Walt Whitman, "aquí la vida no es noble, ni buena, ni sagrada" (p. 220). En este sentido, la solidaridad con los negros, además de su comprensión simpática por marginados, hay que entenderla, porque "ellos -como precisa Lorca- ejercen enorme influencia en Norteamérica y, pese a quien pese, son lo más espiritual y lo más delicado de aquel mundo"51; pero, en contrapunto negativo, el mismo Lorca subraya "el dolor que tienen los negros de ser negros en un mundo contrario, esclavos de todos los inventos del hombre blanco y de todas sus máquinas" (Ibid. p. 114). La imagen de Wall Street, desde este punto de vista de la espiritualidad, es definitivamente concluyente, pues "en ningún sitio del mundo se siente como allí la ausencia total del espíritu" (Ibid p.118). Los poemas, en fin, que señalan, desde el título, la Huida de Nueva York, se subtitulan significativamente Dos valses hacia la civilización, lo que implica rechazar como civilización todo lo que deja atrás, es decir, la violenta pesadilla de la gran metrópoli. Y ahora comprendemos mejor, tras la visión del mundo desnaturalizado, deshumanizado, materialista de la megápolis neoyorquina y de la civilización anglosajona, su explosión de júbilo cuando "el barco se aleja y comienzan a llegar, palma y canela, los perfumes de la América con raíces, la América de Dios, la América española. ¿Pero qué es esto? ¿Otra vez España? ¿Otra vez la Andalucía mundial?" (Ibid. p. 124. Eso es: la contigüidad -tan unitaria como diversa- de la América española, de España y de la Andalucía mundial, que conforma el subespacio de la civilización latina versus el que corresponde a la civilización anglosajona. Desde esta perspectiva, la mirada que ha verbalizado la realidad neoyorquina necesariamente había de ser negativa, pesimista, de protesta y denuncia, de rebeldía formal, de apocalipsis y vaticinio, porque esa mirada era una mirada andaluza -y, por contigüidad contextual y subespacial, latinoamericana y española-, trasladada a un subespacio cultural antinómico ${ }^{52}$ en el que, como certifica el propio Lorca, "Nadie puede hacerse una idea [de] la soledad que siente allí un español y más todavía si éste es un hombre del sur"53.

\footnotetext{
${ }^{51}$ Federico García Lorca, "Un poeta en Nueva York", en Poesía, op. cit., p. 113.

52 Consideramos, claro está, que el espacio del texto adquiere significado sobre el fondo de una imagen del mundo, cuya construcción organizan "los modelos históricos y lingüísticos del espacio", según Yuri M. Lotman, Estructura del Texto Artístico, op. cit.; remitimos al mismo libro para la interrelación que suscitan los códigos antinómicos y los subespacios modelizados según tales códigos.

53 Federico García Lorca, "Un poeta en Nueva York", op. cit., p. 120.
} 